\title{
Study on Degradation Kinetics of Co-metabolic Biodegradation of Linear Alkylbenzene Sulfonate Strains
}

\author{
RAN Zhi-lin ${ }^{1 a}$, ZHU jia ${ }^{2 * b}$, ZHOU Li ${ }^{3 c}$, JI Rui-wu ${ }^{3 c}$
}

1. School of Transportation and Environment, Shenzhen Institute of Information Technology, Shenzhen 518172, China;

2. Department of Building and Environmental Engineering,Shenzhen Polytechnic Institute, Shenzhen 518055,China;

\author{
3. School of Environment and Municipal Engineering,Qingdao Technological University,Qingdao \\ 266033,China \\ aranzl@sziit.edu.cn, b110466575@qq.com, ${ }^{\mathrm{c}} 1533909364 @ q q . c o m$
}

Keywords: Linear Alkylbenzene Sulfonate; Co-metabolic; Biodegradation

ABSTRACT.The degradation kinetics of co-metabolic biodegradation of two linear alkylbenzene sulfonate (LAS) strains was researched. Two bacterial strains which could degrade linear alkylbenzene sulfonate by co-metabolism mechanism, named as L-2 and L-15 were determined to Klebsiella sp.and Enterobacter sp.The optimal degradation conditions of L-2 and L-15 were investigated by the orthogonal experiment.The results suggested that the degradation rate of LAS $(50 \mathrm{mg} / \mathrm{L})$ by $\mathrm{L}-2$ was up to $94.2 \%$ when glucose was chosen as growth substrate under the conditions as : $30^{\circ} \mathrm{C}, \mathrm{pH} 7.5$, glucose concentration $500 \mathrm{mg} / \mathrm{L}$, while the degradation rate of LAS (50mg/L) by L-15 was up to $92.2 \%$ under the conditions as: $30^{\circ} \mathrm{C}$, $\mathrm{pH} 7.5$, glucose concentration $1000 \mathrm{mg} / \mathrm{L}$. The degradation reactions were consistent with characteristics of first-order kinetics when the concentration of LAS ranged from $25 \mathrm{mg} / \mathrm{L}$ to $100 \mathrm{mg} / \mathrm{L}$. Certain theoretical basis of the treatment of LAS wastewater was provided by this study.

\section{Introduction}

Linear alkylbenzene sulfonate (LAS) is an anionic surfactant which is the main ingredient of synthetic detergent,has been widely used for domestic and industrial purposes ${ }^{[1-2]}$. However,LAS may has a negative impact on the environment during its life-cycle.There remains 20\% 50\% LAS after a long period of degradation,through it is biodegradated easily under aerobic conditions ${ }^{[3]}$. The LAS in wastewater can affect the activity of the enzyme, dissolve the biological membrane of microorganisms and invertebrates, damage the structure of the protein and endanger the health of animals and plants ${ }^{[4-7]}$. Therefore, the method of removing LAS in wastewater high efficiently has become a hot research topic. The methods of treating LAS mainly include physical separation, catalytic oxidation and biological treatment at present. The biological treatment method, which has the advantages of large scale, simple equipment, low cost and wide application, is the most studied method.

Two bacterial strains which could degrade linear alkylbenzene sulfonate by co-metabolism mechanism, named as L-2 and L-15 were isolated from sewage treatment plant and determined to Klebsiella sp.and Enterobacter sp.before this experiment.Degradations of linear alkylbenzene sulfonate by L-2 and L-15 were optimized by varying the culture temperature,pH,the volume of culture fluid and the glucose concentration. The degradation kinetics was analyzed while LAS of different concentrations were degraded by L-2 and L-15.

\section{Materials and methods}

\section{Medium}

The component of the Medium (g/L): $\mathrm{MgSO}_{4} \cdot 7 \mathrm{H}_{2} \mathrm{O} \quad 0.14, \mathrm{Ka}_{2} \mathrm{HPO}_{4} 0.43, \mathrm{KaCl} 0.06, \mathrm{FeSO}_{4} \cdot 7 \mathrm{H}_{2} \mathrm{O}$ $0.005, \mathrm{NH}_{4} \mathrm{Cl}$ 0.75,LAS 0.05. 


\section{Experimental instrument}

Full temperature oscillator(HZQ-FX,Harbin Donglian Electronic Technology Co. Ltd.), Autoclave (HVE-50, Hirayama, Japan), Upright fluorescence microscope (BX51, Olympus, Japan), Microcentrifuge(MIKRO 200R, Hettich, Germany), Fluorescent spectrophotometer (F-7000, Hitachi, Japan), Electronic balance (BS-124S,Sartorius,Germany)

\section{Methods}

LAS was determined using a fluorescent spectrophotometer.The medium was centrifuged at $8000 \mathrm{r} / \mathrm{min}$ by 10 minutes after it was put into the centrifuge tube.Then, $1.0 \mathrm{ml}$ supernatant was removed into $25 \mathrm{ml}$ colorimetric tube. Taking $5 \mathrm{ml}$ of $\mathrm{NH}_{3} \cdot \mathrm{H}_{2} \mathrm{O}-\mathrm{NH}_{4} \mathrm{Cl}$ buffer solution $(\mathrm{pH}=10.6)$ into the $25 \mathrm{ml}$ colorimetric tube mentioned above.The fluorescence intensity $\mathrm{F}$ was measured at the excitation wavelength of $230 \mathrm{~nm}$, the emission wavelength of $290 \mathrm{~nm}$. The concentration of LAS was obtained from the standard curve according to the fluorescence intensity $\mathrm{F}$ measured.

In this experiment,the two bacteria strains were inoculated in the culture medium. Degradations were optimized by varying the culture temperature, $\mathrm{pH}$, the volume of culture fluid and the glucose concentration. LAS concentrations were detected, and the degradation rate of LAS was calculated after the medium in $250 \mathrm{ml}$ conical flask was cultured for 5 days in full temperature oscillator.Under the optimal degradation conditions, the degradation rate of LAS by L- 2 and L- 15 was fitted by Monod equation.

\section{Results}

\section{The orthogonal experiment}

This orthogonal experiment contains the factors of the culture temperature(A),pH(B), the volume of medium (C) and the glucose concentration(D). Table 1 reflects the level of each factor . Orthogonal experiment analysis table 2 and 3 reflect the degradation rate of LAS in the different levels of different factors after cultured for 120 hours.

Table 1.The different factors and levels in orthogonal experiment

\begin{tabular}{|c|c|c|c|c|c|}
\hline Level & emperature (A) $/{ }^{\circ} \mathrm{C}$ & $\mathrm{pH} /(\mathrm{B})$ & \multicolumn{2}{|c|}{ Volume of medium $(\mathrm{C}) / \mathrm{ml}$} & Glucose concentration $(\mathrm{D})(\mathrm{g}$ \\
\hline 1 & 30 & 6.5 & \multicolumn{2}{|c|}{50} & 100 \\
\hline 2 & 20 & 8.5 & \multicolumn{2}{|c|}{100} & 500 \\
\hline 3 & 40 & 7.5 & \multicolumn{2}{|c|}{150} & 1000 \\
\hline \multicolumn{6}{|c|}{ Table 2.The degradation analysis of L-2 in the orthogonal experiment } \\
\hline Number & A & B & $\mathrm{C}$ & $\mathrm{D}$ & L-2 degradation/\% \\
\hline 1 & 1 & 1 & 1 & 1 & 34.9 \\
\hline 2 & 1 & 2 & 2 & 2 & 57.6 \\
\hline 3 & 1 & 3 & 3 & 3 & 69.3 \\
\hline 4 & 2 & 1 & 2 & 3 & 25.1 \\
\hline 5 & 2 & 2 & 3 & 1 & 16.1 \\
\hline 6 & 2 & 3 & 1 & 2 & 68.3 \\
\hline 7 & 3 & 1 & 3 & 2 & 16.6 \\
\hline 8 & 3 & 2 & 1 & 3 & 42.9 \\
\hline 9 & 3 & 3 & 2 & 1 & 11.9 \\
\hline $\mathrm{K}_{1}$ & 161.8 & 76.6 & 146.1 & 62.9 & \\
\hline $\mathrm{K}_{2}$ & 109.5 & 116.6 & 94.6 & 142.5 & \\
\hline $\mathrm{K}_{3}$ & 71.4 & 149.5 & 102 & 137.3 & \\
\hline $\mathrm{k}_{1}$ & 53.9 & 25.5 & 48.7 & 21.0 & \\
\hline $\mathrm{k}_{2}$ & 36.5 & 38.9 & 31.5 & 47.5 & \\
\hline $\mathrm{k}_{3}$ & 23.8 & 49.8 & 34 & 45.8 & \\
\hline Range & 30.1 & 24.4 & 17.2 & 26.5 & \\
\hline Order & & & $>\mathrm{B}>\mathrm{C}$ & & \\
\hline Optimal leve & 30 & 7.5 & 50 & 500 & \\
\hline
\end{tabular}


Table 3.The degradation analysis of L-15 in the orthogonal experiment

\begin{tabular}{cccccc}
\hline Number & $\mathrm{A}$ & $\mathrm{B}$ & $\mathrm{C}$ & $\mathrm{D}$ & L-2 degradation/\% \\
\hline 1 & 1 & 1 & 1 & 1 & 34.9 \\
2 & 1 & 2 & 2 & 2 & 57.6 \\
3 & 1 & 3 & 3 & 3 & 69.3 \\
4 & 2 & 1 & 2 & 3 & 25.1 \\
5 & 2 & 2 & 3 & 1 & 16.1 \\
6 & 2 & 3 & 1 & 2 & 68.3 \\
7 & 3 & 1 & 3 & 2 & 42.6 \\
8 & 3 & 2 & 1 & 3 & 11.9 \\
9 & 3 & 3 & 2 & 1 & \\
$\mathrm{~K}_{1}$ & 199.5 & 72.8 & 123.9 & 57.3 & \\
$\mathrm{~K}_{2}$ & 85.8 & 119.5 & 110.5 & 136.8 & \\
$\mathrm{~K}_{3}$ & 58.1 & 151.1 & 109 & 149.3 & \\
$\mathrm{k}_{1}$ & 66.5 & 24.3 & 41.3 & 19.1 & \\
$\mathrm{k}_{2}$ & 28.6 & 39.8 & 36.8 & 45.6 & \\
$\mathrm{k}_{3}$ & 19.4 & 50.4 & 36.3 & 49.7 & \\
Range & 47.1 & 26.1 & 5 & 30.6 & \\
Order & & \multicolumn{5}{c}{$\mathrm{A}>\mathrm{D}>\mathrm{B}>\mathrm{C}$} & & \\
Optimal level & 30 & 7.5 & 50 & 1000 & \\
\hline
\end{tabular}

For the factor $A$,the experiments 1,2 and 3 reflect the influence of $A_{1}$ on the degradation, while 4,5 and 6 reflect the influence of $A_{2}, 7,8$ and 9 reflect the influence of $A_{3}$. The influence on the degradation rate of $A_{1}, A_{2}, A_{3}$ can be judged by the value of $k_{A 1}, k_{A 2}, k_{A 3}$. $A_{1}$ is the optimal level of $A$ factor since $\mathrm{k}_{\mathrm{A} 1}>\mathrm{k}_{\mathrm{A} 2}>\mathrm{k}_{\mathrm{A} 3}$. According to the same method, $\mathrm{B}_{3}, \mathrm{C}_{1}$ and $\mathrm{D}_{2}$ are the optimal level of $\mathrm{B}, \mathrm{C}$ and $\mathrm{D}$.

\section{Kinetics}

The degradation of LAS wastewater with initial concentration of $25,50,100 \mathrm{mg} / \mathrm{L}$ was studied. The results are shown in Fig.1.
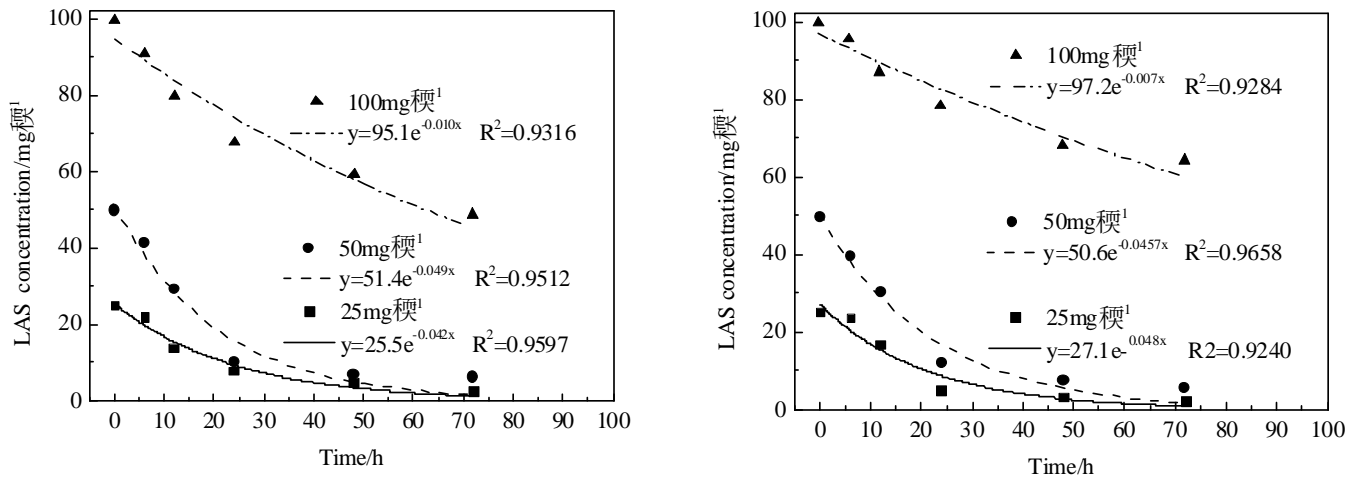

Fig. 1 The degradation of different initial LAS concentrations under the optimal condition by L-2 and L-15

As shown in the Fig.1, the concentration of LAS decreased exponentially. The concentration of LAS decreased rapidly at the initial stage, and then slowly. The fitting curves accorded with first order reaction kinetics equation.The general reaction process can be expressed as the following:

Where:

$$
V=\nabla_{m} c /(k+c)
$$

$\mathrm{V}=$ Reaction rate, $\mathrm{t}^{-1}$

$\mathrm{V}_{\mathrm{m}}=$ The maximum reaction rate, $\mathrm{t}^{-1}$

$\mathrm{C}=$ Concentration of substrate, $\mathrm{mg} / \mathrm{L}$

$\mathrm{k}=$ The half-saturation constant of reaction rate

When the degradation reaction follows the first order kinetic equation and $\mathrm{C}<<\mathrm{k}$, Eq. (1) can be expressed as:

$$
V=V_{m} C / k
$$

$\mathrm{k}_{0}=\mathrm{V}_{\mathrm{m}} / \mathrm{k}$, The relationship between concentration of substrate and time is the following: 


$$
\mathrm{C}=\mathrm{C}_{0} \mathrm{~F}^{-\mathrm{k}_{2} \mathrm{t}}
$$

Table 4.The degradation kinetic equation of L-2

\begin{tabular}{|c|c|c|c|}
\hline LAS concentration $(\mathrm{mg} / \mathrm{L})$ & Degradation kinetic equation & $\mathrm{k}_{0}\left(\mathrm{~h}^{-1}\right)$ & $\mathrm{R}^{2}$ \\
\hline $\begin{array}{c}25 \\
50 \\
100 \\
\end{array}$ & $\begin{array}{l}C=25.5 \mathrm{e}^{-0.042 t} \\
C=51.4 \mathrm{e}^{-0.049 t} \\
C=95.1 \mathrm{e}^{-0.010 t}\end{array}$ & $\begin{array}{l}0.042 \\
0.049 \\
0.010 \\
\end{array}$ & $\begin{array}{l}0.9597 \\
0.9512 \\
0.9316 \\
\end{array}$ \\
\hline \multicolumn{4}{|c|}{ Table 5.The degradation kinetic equation of L-15 } \\
\hline LAS concentration $(\mathrm{mg} / \mathrm{L})$ & Degradation kinetic equation & $\mathrm{k}_{0}\left(\mathrm{~h}^{-1}\right)$ & $\mathrm{R}^{2}$ \\
\hline $\begin{array}{c}25 \\
50 \\
100 \\
\end{array}$ & $\begin{array}{l}\mathrm{C}=27.1 \mathrm{e}^{-0.048 \mathrm{t}} \\
\mathrm{C}=50.6 \mathrm{e}^{-0.046 \mathrm{t}} \\
\mathrm{C}=97.2 \mathrm{e}^{-0.007 \mathrm{t}}\end{array}$ & $\begin{array}{l}0.048 \\
0.046 \\
0.007\end{array}$ & $\begin{array}{l}0.9240 \\
0.9658 \\
0.9284\end{array}$ \\
\hline
\end{tabular}

The degradation kinetic equation of LAS in different sets of experiment is compared in Table 3. and Table 4. Under different initial LAS concentrations conditions, the actual value of LAS degradation rate is in good agreement with the theoretical value. The fitting correlation coefficient squared R2 were all above 0.92. With the increase of the initial concentration of LAS, the constant of reaction rate increased first and then decreased. The growth and reproduction of the bacterias were inhibited, and the metabolic activity slowed down because of the toxicity of LAS when the initial concentration was higher than $50 \mathrm{mg} / \mathrm{L}$. Therefore, the degradation rate of LAS declined, and this belongs to the typical inhibition kinetics.

\section{Conclusions}

This prelimunary study indicated that under the conditions of $30^{\circ} \mathrm{C}, \mathrm{pH} 7.5$, the degradation rate of LAS $(50 \mathrm{mg} / \mathrm{L})$ by L-2 was up to $94.2 \%$ when glucose which concentration was $500 \mathrm{mg} / \mathrm{L}$ was chosen as growth substrate, and the degradation rate by L-15 was $92.2 \%$ when the concentration of glucose was $1000 \mathrm{mg} / \mathrm{L}$. The reactions were in accordance with the first order kinetic equation when the initial concentration of LAS was less than $100 \mathrm{mg} / \mathrm{L}$.

\section{Acknowledgements}

This work was financially supported by the Shenzhen Science Foundation (JCYJ20140508155916418).

\section{REFERENCES}

[1] Nomura Y, Ikebukuro K, Yokoyama K, et al. Application of a linear alkylbenzene sulfonate biosensor to river water monitoring[J]. Biosensors and Bioelectronics, 1998, 13(9): 1047-1053.

[2] Schleheck D, Lechner M, Schönenberger R, et al. Desulfonation and degradation of the disulfodiphenylethercarboxylates from linear alkyldiphenyletherdisulfonate surfactants[J]. Applied and environmental microbiology, 2003, 69(2): 938-944.

[3] Mungray A K, Kumar P. Fate of linear alkylbenzene sulfonates in the environment: a review[J]. International Biodeterioration \& Biodegradation, 2009, 63(8): 981-987.

[4] Jensen J. Fate and effects of linear alkylbenzene sulphonates (LAS) in the terrestrial environment[J]. Science of the total environment, 1999, 226(2): 93-111.

[5] Bragadin M, Perin G, Raccanelli S, et al. The accumulation in lysosomes of the anionic detergent linear alkylbenzene sulfonate[J]. Environmental toxicology and chemistry, 1996, 15(10): 1749-1751.

[6] Cserháti T, Forgács E, Oros G. Biological activity and environmental impact of anionic surfactants[J]. Environment international, 2002, 28(5): 337-348.

[7] Duarte I C S, Oliveira L L, Saavedra N K, et al. Treatment of linear alkylbenzene sulfonate in a horizontal anaerobic immobilized biomass reactor[J]. Bioresource technology, 2010, 101(2): 606-612. 